\title{
Inhibition of mitochondrial permeability transition pore opening: the holy grail of cardioprotection
}

\author{
Gerd Heusch $\cdot$ Kerstin Boengler • Rainer Schulz
}

Published online: 12 January 2010

(C) Springer-Verlag 2009

Cardioprotection is a fairly vague term which refers to the reduction of damage from myocardial ischemia/reperfusion by several endogenous phenomena, such as hibernation [23, 37], ischemic preconditioning [32, 41], ischemic postconditioning [20,43], and remote conditioning [19, 22] as well as by pharmacological interventions. With the recognition of the postconditioning phenomenon [43], myocardial reperfusion injury has been appreciated as a reality [42] from which protection is clinically feasible [36, $38,39]$. The signal transduction of cardioprotection is under intense investigation, with the ultimate aim to identify targets for pharmacological recruitment of cardioprotection [21]; three major pathways have been characterized-the cGMP/PKG-pathway [11], the reperfusion injury salvage kinase (RISK)-pathway [18] and the survivor activating factor enhancement (SAFE)-pathway [31]. These three major pathways are not mutually exclusive, but potentially cooperative, and they are recruited by the above cardioprotective phenomena to a different extent.

The cardioprotective signaling pathways are thought to converge on the mitochondria [21], and various mitochondrial proteins without or with channel structure have been identified as central elements in cardioprotection. Several signaling pathways of cardioprotection converge to inhibit glycogen synthase kinase- $3 \beta$ which in its phosphorylated state increases the threshold for mitochondrial permeability transition pore (MPTP) opening [25, 26].

G. Heusch $(\bowtie) \cdot$ K. Boengler $\cdot$ R. Schulz

Institute for Pathophysiology,

University of Essen Medical School,

Hufelandstr. 55, 45122 Essen, Germany

e-mail: gerd.heusch@uk-essen.de
The MPTP is a large-conductance megachannel which is traditionally thought to be formed by an arrangement of the voltage-dependent anion channel (VDAC) in the outer mitochondrial membrane, the adenine nucleotide transporter (ANT) in the inner membrane and cyclophilin D in the matrix [30]. The MPTP is either not present or mostly closed under physiological conditions, but opens in response to high concentrations of calcium. The calciuminduced opening of MPTP is favoured by high concentrations of inorganic phosphate, reactive oxygen species, and nitric oxide and a reduction of the inner membrane potential-all conditions which occur during myocardial ischemia and reperfusion; acidosis and magnesium ions inhibit/delay MPTP opening [8, 13, 29, 30, 40, 44]. In addition, pro- and anti-apoptotic members of the Bcl-family interact with the MPTP [3]. Formation and opening of the MPTP results in depolarization of the inner membrane potential and matrix swelling and ultimately in rupture of the outer membrane. Proteins, among them cytochrome $\mathrm{C}$, are then released from the intermembrane space into the cytosol and activate caspase cascades to initiate cellular fragmentation and ultimately cell death.

In 1993, both the groups of Crompton [12] and Halestrap [16] demonstrated that MPTP opened upon reperfusion following myocardial ischemia and that cyclosporine A protected from reperfusion injury. Cyclosporine A inhibits binding of cyclophilin D to ANT, thereby MPTP opening and ultimately cell death; ablation of the Ppif gene which encodes for cyclophilin D [4, 33] and cyclosporine A [4] therefore reduce infarct size resulting from myocardial ischemia and reperfusion.

Yellon et al. first proposed that inhibition of MPTP opening could be the effector of ischemic preconditioning [17], and Ovize et al. shortly thereafter proposed MPTP inhibition as the effector of ischemic postconditioning [2]; 
their experimental evidence was largely based on the use of MPTP inhibition by cyclosporine A or its non-immunosuppressive derivative and analysis of respective changes in the calcium retention capacity of isolated mitochondria.

Mechanistic analyses of MPTP are derived from biochemistry of purified and reconstituted putative constituent proteins, from electrophysiology of isolated mitoplasts and/ or mitochondria and from confocal microscopy using marker molecules and dyes in isolated cells. The involvement of the MPTP is obviously more difficult to identify in ischemic/ reperfused myocardium in vivo, and evidence for the involvement of the MPTP in vivo is therefore largely indirect, e.g. using genetic ablation of putative constituent proteins or pharmacological inhibitors such as cyclosporine A.

Apart from quantitative analysis of mitochondrial depolarization using the fluorescent probe tetramethylrhodamine ethyl ester (TMRE) which may, however, not be specific for MPTP opening [34], the determination of calcium retention capacity in isolated cardiac mitochondria has recently emerged as a popular tool to address the mitochondrial resistance to MPTP opening, and changes in calcium retention capacity may occur independently from changes in membrane potential [35]. Originally this method was developed in liver mitochondria where exposure to pulses of extramitochondrial calcium was buffered by calcium uptake into the mitochondrial matrix such that the extramitochondrial calcium concentration returned back to baseline upon each pulse until finally the extramitochondrial calcium concentration abruptly and markedly increased, presumably secondary to massive calcium release from open MPTP [24]. Now, for proper interpretation of calcium retention capacity in the context of MPTP opening, the functional viability of the mitochondria after isolation must be ascertained; this is most convincingly done by the determination of their respiratory capacity. Respiration should be measured using complex I substrates, because electron flux through complex I is essential to maintain the sensitivity of MPTP for opening [14]. Respiration should not only be measured at baseline, but also with stimulation by ADP and finally with uncoupling using substances such as dinitrophenol or FCCP (carbonylcyanide-4-(trifluoromethoxy)-phenylhydrazone) [9]. The comparison of calcium retention capacity between two different mitochondrial preparations, e.g. protected versus non-protected, can only be interpreted in relation to their respective respiratory capacity. Given proper determination of respiration, it is then essential to observe a true return of the extramitochondrial calcium concentration back to baseline to make sure that all mitochondria in the given population under study still have their MPTP closed, before after several calcium pulses with return to baseline an abrupt and massive calcium release is detected [6]. The comparison of mitochondrial preparations undergoing different interventions by the amount of calcium needed to induce MPTP opening assumes that baseline calcium load is comparable; in fact, reperfusion per se increases mitochondrial calcium, and preconditioning but not postconditioning attenuates this increase [1]. The administration of exogenous cyclosporine $\mathrm{A}$ and the consequent delay of MPTP opening should be part of each protocol to determine mitochondrial calcium retention capacity. With use of cyclosporine A, however, only the role of cyclophilin D in MPTP opening is assessed [6]. With measurement of mitochondrial calcium retention capacity in the absence and in the presence of cyclosporine $\mathrm{A}$, therefore, the cyclophilin D-dependent and -independent alterations in MPTP opening can be determined; the cyclophilin D-independent changes in MPTP opening might reflect the regulator, e.g. inorganic phosphate $[13,15]$.

Apart from these important technical considerations, conceptually data on calcium retention capacity from isolated mitochondria ex vivo can only be retrospectively associated to the observed infarction and protection from it, but can never be put into a causal context: is better calcium retention capacity ex vivo cause or consequence of reduced infarct size in vivo? Finally, not all mitochondria are created equal, and there may be differences between subsarcolemmmal and interfibrillar mitochondria which are relevant for cardioprotection [10].

The traditional view of the MPTP is far from firmly established; each single putative constituent of the MPTP appears dispensable under certain conditions [8, 44]: VDAC [5, 28], ANT [27], and cyclophilin D [6, 7]. From a pragmatic point of view, however, cyclosporine A when given at reperfusion clearly reduced infarct size by about $40 \%$ in a clinical proof-of-concept study [36]; whether or not such protection translates into improved prognosis remains to be seen in larger-scale prospective trials.

In the end, inhibition of the MPTP is indeed like a holy grail in cardioprotection: it is an extremely attractive target, but the true identity and precise function of the MPTP in myocardial ischemia/reperfusion remain enigmatic and elusive-you just have to believe in it, or not.

\section{References}

1. Argaud L, Gateau-Roesch O, Augeul L, Couture-Lepetit E, Loufouat J, Gomez L, Robert D, Ovize M (2008) Increased mitochondrial calcium coexists with decreased reperfusion injury in postconditioned (but not preconditioned) hearts. Am J Physiol Heart Circ Physiol 294:H386-H391

2. Argaud L, Gateau-Roesch O, Raisky O, Loufouat J, Robert D, Ovize M (2005) Postconditioning inhibits mitochondrial permeability transition. Circulation 111:194-197

3. Baines CP (2009) The mitochondrial permeability transition pore and ischemia-reperfusion injury. Basic Res Cardiol 104:181-188 
4. Baines CP, Kaiser RA, Purcell NH, Blair NS, Osinska H, Hambleton MA, Brunskill EW, Sayen MR, Gotlieb RA, Dorn GW II, Robbins J, Molkentin JD (2005) Loss of cyclophilin D reveals a critical role for mitochondrial permeability transition in cell death. Nature 434:658-662

5. Baines CP, Kaiser RA, Sheiko T, Craigen WJ, Molkentin JD (2007) Voltage-dependent anion channels are dispensable for mitochondrial-dependent cell death. Nat Cell Biol 9:550-555

6. Basso E, Fante L, Fowlkes J, Petronilli V, Forte MA, Bernardi P (2005) Properties of the permeability transition pore in mitochondria devoid of Cyclophilin D. J Biol Chem 280:1855818561

7. Basso E, Petronilli V, Forte MA, Bernardi P (2008) Phosphate is essential for inhibition of the mitochondrial permeability transition pore by cyclosporin a and by cyclophilin D ablation. J Biol Chem 283:26307-26311

8. Bernardi P, Krauskopf A, Basso E, Petronilli V, Blachly-Dyson E, Di LF, Forte MA (2006) The mitochondrial permeability transition from in vitro artifact to disease target. FEBS $\mathrm{J}$ 273:2077-2099

9. Boengler K, Gres P, Dodoni G, Konietzka I, Di LF, Heusch G, Schulz R (2007) Mitochondrial respiration and membrane potential after low-flow ischemia are not affected by ischemic preconditioning. J Mol Cell Cardiol 43:610-615

10. Boengler K, Stahlhofen S, van de SA, Gres P, Ruiz-Meana M, Garcia-Dorado D, Heusch G, Schulz R (2009) Presence of connexin 43 in subsarcolemmal, but not in interfibrillar cardiomyocyte mitochondria. Basic Res Cardiol 104:141-147

11. Burley DS, Ferdinandy P, Baxter GF (2007) Cyclic GMP and protein kinase- $G$ in myocardial ischaemia-reperfusion: opportunities and obstacles for survival signaling. $\mathrm{Br} \mathrm{J}$ Pharmacol 152:855-869

12. Crompton M, Andreeva L (1993) On the involvement of a mitochondrial pore in reperfusion injury. Basic Res Cardiol 88:513-523

13. Di Lisa F, Bernardi P (2009) A CaPful of mechanisms regulating the mitochondrial permeability transition. J Mol Cell Cardiol 46:775-780

14. Fontaine E, Ichas F, Bernardi P (1998) A ubiquinone-binding site regulates the mitochondrial permeability transition pore. J Biol Chem 273:25734-25740

15. Giorgio V, Bisetto E, Soriano ME, Dabbeni-Sala F, Basso E, Petronilli V, Forte MA, Bernardi P, Lippe G (2009) Cyclophilin D modulates mitochondrial F0F1-ATP synthase by interacting with the lateral stalk of the complex. J Biol Chem 284:33982-33988

16. Griffiths EJ, Halestrap AP (1993) Protection by Cyclosporin A of ischemia/reperfusion-induced damage in isolated rat hearts. J Mol Cell Cardiol 25:1461-1469

17. Hausenloy DJ, Maddock HL, Baxter GF, Yellon DM (2002) Inhibiting mitochondrial permeability transition pore opening: a new paradigm for myocardial preconditioning? Cardiovasc Res 55:534-543

18. Hausenloy DJ, Yellon DM (2004) New directions for protecting the heart against ischaemia-reperfusion injury: targeting the reperfusion injury salvage kinase (RISK)-pathway. Cardiovasc Res 61:448-460

19. Hausenloy DJ, Yellon DM (2008) Remote ischaemic preconditioning: underlying mechanisms and clinical application. Cardiovasc Res 79:377-386

20. Heusch G (2004) Postconditioning. Old wine in a new bottle? J Am Coll Cardiol 44:1111-1112

21. Heusch G, Boengler K, Schulz R (2008) Cardioprotection: nitric oxide, protein kinases, and mitochondria. Circulation 118:19151919

22. Heusch G, Schulz R (2002) Remote preconditioning. J Mol Cell Cardiol 34:1279-1281
23. Heusch G, Schulz R, Rahimtoola SH (2005) Myocardial hibernation: a delicate balance. Am J Physiol Heart Circ Physiol 288:H984-H999

24. Ichas F, Jouaville LS, Sidash SS, Mazat JP, Holmuhamedov EL (1994) Mitochondrial calcium spiking: a transduction mechanism based on calcium-induced permeability transition involved in cell calcium signalling. FEBS Lett 348:211-215

25. Juhaszova M, Zorov DB, Kim S-H, Pepe S, Fu Q, Fishbein KW, Ziman BD, Wang S, Ytrehus K, Antos CL, Olson EN, Sollott SJ (2004) Glycogen synthase kinase-3 $\beta$ mediates convergence of protection signaling to inhibit the mitochondrial permeability transition pore. J Clin Invest 113:1535-1549

26. Juhaszova M, Zorov DB, Yaniv Y, Nuss HB, Wang S, Sollott SJ (2009) Role of glycogen synthase kinase-3beta in cardioprotection. Circ Res 104:1240-1252

27. Kokoszka JE, Waymire KG, Levy SE, Sligh JE, Cai J, Jones DP, MacGregor GR, Wallace DC (2004) The ADP/ATP translocator is not essential for the mitochondrial permeability transition pore. Nature 427:461-465

28. Krauskopf A, Eriksson O, Craigen WJ, Forte MA, Bernardi P (2006) Properties of the permeability transition in VDAC1(-/-) mitochondria. Biochim Biophys Acta 1757:590-595

29. Kroemer G, Galluzzi L, Brenner C (2007) Mitochondrial membrane permeabilization in cell death. Physiol Rev 87:99-163

30. Kroemer G, Reed JC (2000) Mitochondrial control of cell death. Nat Med 6:513-519

31. Lecour S (2009) Activation of the protective survivor activating factor enhancement (SAFE) pathway against reperfusion injury: does it go beyond the RISK path? J Mol Cell Cardiol 47:32-40

32. Murry CE, Jennings RB, Reimer KA (1986) Preconditioning with ischemia: a delay of lethal cell injury in ischemic myocardium. Circulation 74:1124-1136

33. Nakagawa T, Shimizu S, Watanabe T, Yamaguchi O, Otsu K, Yamagata H, Inohara H, Kubo T, Tsujimoto Y (2005) Cyclophilin D-dependent mitochondrial permeability transition regulates some necrotic but not apoptotic cell death. Nature 434:652-658

34. O'Reilly CM, Fogarty KE, Drummond RM, Tuft RA, Walsh JV Jr (2003) Quantitative analysis of spontaneous mitochondrial depolarizations. Biophys J 85:3350-3357

35. Paillard M, Gomez L, Augeul L, Loufouat J, Lesnefsky EJ, Ovize M (2009) Postconditioning inhibits mPTP opening independent of oxidative phosphorylation and membrane potential. J Mol Cell Cardiol 46:902-909

36. Piot C, Croisille P, Staat P, Thibault H, Rioufol G, Mewton N, Elbelghiti R, Cung TT, Bonnefoy E, Angoulvant D, Macia C, Raczka F, Sportouch C, Gahide G, Finet G, Andre-Fouet X, Revel D, Kirkorian G, Monassier J-P, Derumeaux G, Ovize M (2008) Effect of cyclosporine on reperfusion injury in acute myocardial infarction. N Engl J Med 359:473-481

37. Rahimtoola SH (1985) A perspective on the three large multicenter randomized clinical trials of coronary bypass surgery for chronic stable angina. Circulation 72(Suppl V):V-123-V-135

38. Staat P, Rioufol G, Piot C, Cottin Y, Cung TT, L'Huillier I, Aupetit J-F, Bonnefoy E, Finet G, Andre-Fouet X, Ovize M (2005) Postconditioning the human heart. Circulation 112:21432148

39. Thibault H, Piot C, Staat P, Bontemps L, Sportouch C, Rioufol G, Cung TT, Bonnefoy E, Angoulvant D, Aupetit JF, Finet G, Andre-Fouet X, Macia JC, Raczka F, Rossi R, Itti R, Kirkorian G, Derumeaux G, Ovize M (2008) Long-term benefit of postconditioning. Circulation 117:1037-1044

40. Weiss JN, Korge P, Honda HM, Ping P (2003) Role of the mitochondrial permeability transition in myocardial disease. Circ Res 93:292-301 
41. Yellon DM, Downey JM (2003) Preconditioning the myocardium: from cellular physiology to clinical cardiology. Physiol Rev 83:1113-1151

42. Yellon DM, Hausenloy DJ (2007) Myocardial reperfusion injury. N Engl J Med 357:1121-1135

43. Zhao Z-Q, Corvera JS, Halkos ME, Kerendi F, Wang N-P, Guyton RA, Vinten-Johansen J (2003) Inhibition of myocardial injury by ischemic postconditioning during reperfusion: comparison with ischemic preconditioning. Am J Physiol Heart Circ Physiol 285:H579-H588

44. Zorov DB, Juhaszova M, Yaniv Y, Nuss HB, Wang S, Sollott SJ (2009) Regulation and pharmacology of the mitochondrial permeability transition pore. Cardiovasc Res 83:213-225 